\title{
Profesores de historia e historiografía estatista: Consideraciones básicas para los estudiantes de Pedagogía en Historia
}

\author{
Teachers of History and Statist Historiography: Basic Regards for \\ Students of Pedagogy in History \\ Professores de História e Historiografia Estatista: Consideracções básicas para \\ estudantes de Pedagogia em História
}

Camilo Santibáñez $R$.

Ayudante Instructor, Departamento de Educación, Universidad de Tarapacá, Chile. Correo electrónico: sntibaez@gmail.com

\begin{abstract}
RESUMEN
Este artículo examina el ejercicio docente del profesorado en historia, interrogando la educación y la historiografía en relación a la reproducción de una ideología estatista que invisibiliza la alteridad y ejerce hegemonía a través de unos saberes revestidos de objetividad. Incompatibles los márgenes del orden con un estudio histórico crítico, el profesorado en historia, como intelectual orgánico inserto en el complejo de relaciones de poder, es caja de resonancia de una historiografía estatista de lenguaje policial o catalizador de la comprensión histórica para las masas estudiantiles, centrando su trabajo en el presente fulgurante.
\end{abstract}

Palabras clave: educación, profesorado en historia, historiografía, hegemonía.

\begin{abstract}
This paper examines the teaching practices of history teachers, questioning the education and historiography in relation to the reproduction of a statist ideology that makes the otherness invisible, exercising hegemony through a coated knowledge which seems objective. Margins of the order appears incompatible with a critical historical study; teachers of history, as an organic intellectual part of the complex relationships of power, are a sound box of a statist historiography of police language or a catalyst of historical understanding for the students' masses focusing their work on the lightning present.
\end{abstract}

Key words: education, teachers of history, historiography, hegemony.

\section{RESUMO}

Analisa-se a prática profissional de professores de História, interroga-se a educação e a Historiografia em relação à reprodução de uma ideologia estatista que invisibiliza a alteridade, exercendo hegemonia por meio de saberes revestidos de objetividade. Margens incompatíveis da ordem com um estudo histórico crítico, o professorado de História, como intelectual orgânico inserido em um complexo de relações de poder, é caixa de ressonância de uma historiografia estatista de linguagem policial ou catalisador da compreensão histórica para as massas estudantis, centrando o seu trabalho no presente fulgurante.

Palavras chave: educação, professores de história, historiografia, hegemonia. 


\section{INTRODUCCIÓN}

Los trabajadores no supieron oponer la violencia a la violencia porque habían sido educados en el respeto de la legalidad.

Errico Malatesta, 1922.

A esta generación de profesores de historia se nos han poblado los bolsillos de inquietudes. ${ }^{1}$ Situados histórica y epistemológicamente, nuestra visibilidad está definida por la construcción de nuestras preguntas y nuestras respuestas, que aquí exponemos como problematización de una complejidad. La ciencia, como toda producción intelectual, está indivisiblemente situada en su construyéndose. La ciencia, dice Popkewitz (2000), no debe confundirse con unas preocupaciones positivistas por reglas y normas abstractas no relacionadas con las condiciones sociales e históricas.

En esta problematización, entendemos el ejercicio docente de enseñar historia como un conjunto de prácticas discursivas ${ }^{2}$ que contienen y gestan articulaciones de dominación o fábricas clandestinas de bombas, como dice Eric J. Hobsbawm (2008); Prácticas que se sitúan históricamente en procesos de subjetivación, contenidos a su vez en articulaciones hegemónicas, que enhebran sujetos históricos y condicionan las rebeldías y las obediencias; las indignaciones, las confianzas y las paciencias; las energías en movimiento.

En consideración de esto, irremediablemente nos preguntamos: ¿Qué articulaciones de subjetivación y hegemonía condicionan ideológicamente nuestro ejercicio docente y sus resultantes? ¿A qué procesos de ortopedia social colaboramos o saboteamos? ¿Cómo estamos pensando los profesores de historia el estado, la dominación, las rebeldías, la policía, la violencia, para delimitar el trabajo con los estudiantes? ¿Pueden los estudiantes hacer una lectura de las condiciones socio-históricas desde la historia que enseñamos?

Sostenemos que tanto la formulación como la resolución de estas preguntas están contenidas en nuestras prácticas docentes, en el examen a sus matrices historiográficas y epistemológicas, y a las relaciones de poder-saber que ellas involucran (Foucault, 2003). El desmonte de estas prácticas discursivas, siempre ideológicas y con implicancias políticas, es primordial para el profesorado de historia, nunca objetivo, nunca únicamente ${ }^{3}$ pedagógico, sino inserto en el complejo de relaciones de poder.

Esto implica referirnos a cómo nos situamos los profesores en dicho tejido de relaciones de poder-saber, que son siempre en última instancia hegemónicas o contrahegemónicas, determinándonos como intelectuales orgánicos. El profesorado de historia entra siempre

1 Dicho a vuelo de pájaro, esto está influenciado, por una parte, por la experiencia contracultural y las nuevas construcciones militantes; y, por otra parte, por el desarrollo historiográfico chileno de las últimas décadas.

2 La categoría de práctica discursiva entendida como unos enunciados sobre una episteme, la base de distribución de un saber, construcción de sus objetos y su dispersión; esto, entendiendo a la vez que los discursos no solo están atravesados por su estructura argumentativa, sino fundamentalmente por las condiciones materiales y contextuales en las que se producen y reproducen.

3 Lucien Febvre respondía rabioso a unos historiadores que circunscribían con un bisturí, en el cerebro de sus sujetos de estudio, un compartimento, separándolo de todo lo que le rodeaba, cortando las arterias y los nervios que le daban vida y luego describían aquella cosa muerta como si la vida no se hubiera retirado (Febvre, 1986). Es necesario que respondamos rabiosos también nosotros, profesores de historia, a unos análisis cercenados, a razonamientos ahistóricos que suponen la existencia de una educación objetiva o neutral, haciendo levitar de ingenuidad los análisis pedagógicos, volviéndolos estériles al reducir su complejidad. 
a un campo de luchas, de construcciones interpretativas que son siempre políticas, de representaciones mediadas por ideologías, directamente relacionadas con las hegemonías en las lecturas del mundo y de los siglos; trabaja con textos, con fuentes históricas e historiográficas, con nociones y conceptos atravesados por conflictos, generados en articulaciones disciplinantes o de resistencia. En nuestra condición de profesorado podemos reforzar o combatir esta dominación, estas correlaciones de fuerzas en las relaciones de poder, pero lo que no podemos permitirnos es ser ingenuos respecto de esto; la ingenuidad del profesor de historia, como señalaremos en otras líneas, lo convierte en un gendarme de la dominación.

En este campo de luchas, los estudiantes tampoco podrían ser ajenos. La comprensión de las complejidades históricas implica interiorizar las relaciones dialécticas que transforman a unos campesinos en insurrectos y a otros en policías, a unos indios en insurgentes $\mathrm{y}$ a otros en gendarmes, a unos pobladores en subversivos y a otros en lumpen, a unos trabajadores en tomadores de fábricas y a otros en rompehuelgas, a unos estudiantes en cortadores de caminos y a otros en reaccionarios o funcionales; y entender también cómo, a la vez, todos ellos transforman y definen los procesos históricos, en huelgas de cacerolas nunca usadas o en cordones industriales, en un helicóptero arrojando cadáveres de detenidos al océano o en la clandestinidad. No se puede pretender construir estudiantes críticos serios sin exponer las contradicciones y conflictos que minan el supuesto sustento de la "unidad nacional", el "orden", la "armonía social".

Este artículo, elaborado desde el interior de la práctica pedagógica, desde las jaulas y los puentes que se trazan y caminan en la clase de historia, intenta desmontar unas nociones ahistóricas, objetivas, de la pedagogía en historia y de sus recurrentes insumos historiográficos, evidenciando la violencia simbólica que ejercen, revirtiéndola de manera consciente en función de un estudio de la historia como experiencia colectiva a disposición de unos estudiantes que hagan la historia.

\section{EDUCACIÓN E IDEOLOGÍA ESTATISTA}

Es primordial comenzar identificando en la escuela una transmisión de una ideología estatal, contenida, adjunta, implícita en unos saberes escolares, expuestos como neutrales, objetivos e incuestionables.

En La Reproducción. Elementos para una teoría del sistema de enseñanza, Pierre Bourdieu y Jean-Claude Passeron (1996) desarrollan unos fundamentos de una teoría de la violencia simbólica. La particular manera de exponer estos fundamentos nos permite resumir su hipótesis en los siguientes axiomas:

0. Todo poder de violencia simbólica, o sea, todo poder que logra imponer significaciones e imponerlas como legítimas disimulando las relaciones de fuerza en que se funda su propia fuerza, añade su fuerza propia, es decir, propiamente simbólica, a esas relaciones de fuerza (44).

1. Toda acción pedagógica (AP) es objetivamente una violencia simbólica en tanto que imposición, por un poder arbitrario, de una arbitrariedad cultural. (45)

Es decir, la arbitrariedad cultural de un poder arbitrario, que en nuestras condiciones históricas es EL ESTADO, ejerce una violencia simbólica porque impone significaciones culturalmente arbitrarias y transforma estas significaciones en legítimas ocultando las 
relaciones de fuerza, de conflicto, de tensión, de dominación y disciplinamiento de las que son fruto, visibilizando e invisibilizando, a la manera de una selección determinante, unos saberes, unos contenidos, presentándolos como una cultura objetiva, neutra, normal. ${ }^{4}$

Michel Foucault (2003), situándose en Nietzsche, nos ha planteado que los saberes surgen de las relaciones de lucha y de dominación, que son indivisibles de las relaciones históricas de poder en las que se originan y que significan toda una construcción y determinación histórica de los regímenes de verdad, configurando lo correcto y lo incorrecto, lo racional y lo irracional, lo normal y lo anormal; lo que correlativamente provoca y determina unos dispositivos de normalización, de disciplina, de control, de ortopedia social.

Louis Althusser (1974), por su parte, ya había señalado la relevancia de lo que nombró aparatos ideológicos de estado (AIE), enfatizando que el aparato ideológico escolar tiene la posición dominante en nuestras formaciones capitalistas maduras, en la reproducción de nuestras relaciones de producción. La escuela, dice Althusser, representada como un medio neutro, desprovisto de ideología, colabora significativamente a reproducir la dominación del estado porque efectivamente difunde unas formaciones teóricas capaces de penetrar en la vida práctica de los hombres, por lo tanto, de inspirar y de animar toda una época histórica, proporcionando a los hombres una visión general del curso del mundo y al mismo tiempo una regla de conducta práctica.

Esta preocupación de Althusser (también, entre otros, de su compañero Nicos Poulantzas, 1986), estaba contenida de manera central en Antonio Gramsci, quien desarrolla instrumentos conceptuales como hegemonía e intelectuales orgánicos, que es conveniente revisar: ${ }^{5}$ Hegemonía en Gramsci es la capacidad de dirigir, de unificar a través de la ideología y de mantener unido un bloque social que, sin embargo, no es homogéneo sino marcado por profundas contradicciones de clase: una clase es hegemónica, dirigente, dominante, mientras con su acción política, ideológica, cultural, logra mantener junto a sí un grupo de fuerzas heterogéneas e impide que la contradicción existente entre estas fuerzas estalle, produciendo una crisis en la ideología dominante y conduciendo a su rechazo (Gruppi, 1978).

Este predominio intelectual, cultural y moral de la clase hegemónica genera una dirección que es asumida por los grupos subalternos, adquiriendo la visión de mundo, los hábitos y valores de los grupos dominantes, resultando de esto un sentido común. Al interiorizar esta hegemonía nos convertimos en nuestros mejores gendarmes: interiorizamos las nociones de lo correcto y lo incorrecto, lo normal y lo anormal e interpretamos con ellas nuestras vidas, condicionando nuestra lectura del mundo y soldando la idea de un solo mundo posible, determinando nuestros comportamientos y voluntades. En suma, las clases o grupos dominantes no sólo dominan a través de la fuerza -aunque nunca dejen de hacerlo- sino que también dirigen a través de la hegemonía ideológica.

En esta lectura de relaciones hegemónicas, los intelectuales adquieren un rol gravitante, que es fructuoso precisar: para Gramsci, los intelectuales no constituyen un grupo social

4 El estado, como poder arbitrario, establece esta selección cultural, ejerce esta violencia simbólica, determinando los contenidos obligatorios (CMO) y los objetivos fundamentales (OF), filtrando los textos de estudio, legitimando los aprendizajes bajo el signo disciplinante de la evaluación (SIMCE, PSU).

5 Estas categorías, que, como bien ha señalado Daniel Campione (2010), se definen y reconstruyen en contacto directo con la realidad, son claves de interpretación histórica y de análisis de procesos. (En línea) 
independiente, sino que están determinados -como lo está su producción, los saberespor su vínculo con las clases, la formación de esta clase y su diseminación ideológica. ${ }^{6}$

Todo este preámbulo resulta útil porque, en primer lugar, niega un saber objetivo: no hay lecturas inocentes, contenidos neutros ni textos ingenuos en tanto los saberes se sitúan en las relaciones de poder y de dominación ideológica; en segundo lugar, vincula estos saberes con la difusión ideológica estatal a través del aparato escolar y la construcción hegemónica de un sentido común, caracterizando el determinante rol político de la educación institucionalizada en la reproducción de la dominación; en tercer lugar, nos sitúa como profesorado en el complejo de relaciones de poder y nos obliga a preguntarnos: Nosotros, profesores, ¿nos hacemos intelectuales orgánicos de la dominación, difundiendo unos saberes vehículos de la ideología estatal? ¿Ejercemos día tras día una ortopedia social a través de una violencia simbólica que legitima la dominación al diseminar esta arbitrariedad cultural? ¿Estamos, profesores, reproduciendo la hegemonía?

Si sintetizamos el problema de la educación estatal como la hemos estado enfocando, ésta reproduce la ideología de las clases dominantes -haciéndola la ideología dominante- bajo el signo de unos saberes situados neutros, que influyen, forman, construyen nuestro sentido común. Este mecanismo de reproducción requiere de unos trabajadores que difundan, que materialicen esta ideología, a quienes llamamos profesores -sobre los que se ejerce también unos instrumentos de control y de disciplinamiento.

Amargamente, Althusser escribía entre las líneas de su trabajo respecto a los AIE:

Pido perdón por esto a los maestros que, en condiciones espantosas, intentan volver contra la ideología, contra el sistema y contra las prácticas de que son prisioneros, las pocas armas que puedan hallar en la historia y el saber que ellos "enseñan". Son una especie de héroes. Pero no abundan, y muchos (la mayoría) no tienen siquiera la más remota sospecha del "trabajo" que el sistema (que los rebasa y aplasta) les obliga a realizar y, peor aún, ponen todo su empeño e ingenio para cumplir con la última directiva. Están tan lejos de imaginárselo que contribuyen con su devoción a mantener y alimentar, esta representación ideológica de la escuela, que la hace tan "natural" e indispensable, y hasta bienhechora, a los ojos de nuestros contemporáneos como la iglesia era "natural", indispensable y generosa para nuestros antepasados hace algunos siglos (1986: 45 y 46).

Ahora bien, una reproducción supone que unos engranajes determinados y determinantes componen un proceso mecánico, inquebrantable, inextinguible que, por definición, es inalterable, indestructible y no hay nada que pueda hacerse. Sin embargo, hay un luminoso reparo -del que nos hacemos parte- planteado por Francesco Ciataloni (1996) a La Reproducción de Bourdieu y Passeron. Ciataloni sostiene que la reproducción de

En palabras de Gramsci: "Cada grupo social, naciendo en el terreno originario de una función esencial en el mundo de la producción económica, se crea al mismo tiempo, orgánicamente, una o más capas de intelectuales que le dan homogeneidad y conciencia de su propia función no sólo en el campo económico, sino también en el social y político: [...] Los intelectuales son los "encargados" por el grupo dominante para el ejercicio de las funciones subalternas de la hegemonía social y del gobierno político, esto es: 1] del consenso "espontáneo" dado por las grandes masas de la población a la orientación imprimida a la vida social por el grupo dominante fundamental, consenso que nace "históricamente" del prestigio (y por lo tanto de la confianza) derivado por el grupo dominante de su posición y de su función en el mundo de la producción; 2] del aparto de coerción estatal que asegura "legalmente" la disciplina de aquellos grupos que no "consienten" ni activa ni pasivamente [...]" (Gramsci, 1986: 355 y 357). 
la cultura de clase no es una reproducción como lo es, por ejemplo, la reproducción de los pelícanos y que:

No se trata de volcar todo en el gran caldero de la lucha de clases y, por lo tanto, renunciar a plantear un programa para una lucha en la escuela en cuanto tal. Se trata de precisar qué está específicamente unido a los intereses de clase dominante en lo que se enseña, qué es o puede ser útil a los intereses de los opresores [...] (1996: 30).

La gran fuerza de la transmisión de una cultura de clase está en el lograr confundir lo que es necesario con lo que es útil sólo para la clase dominante (1996: 31).

Puesto que, si son las mujeres y los hombres quienes confirman o niegan teorías y culturas, y reproducen, modifican o destruyen clases a través de la historia, mediante la praxis y la experiencia colectiva acumulada, ni los profesores ni los estudiantes están condenados a ser reproductores, porque no son objetos -como sí lo es un engranaje- sino sujetos pensantes que tienen la capacidad de intervenir en los procesos, alterar los mecanismos y las correlaciones de fuerzas constituidas -así como también pueden sostenerlas y reforzarlas. Por esto una hegemonía existente es siempre un proceso dinámico, no es inmóvil ni inmodificable, sino un complejo de relaciones, actividades y experiencias, que tiene límites y presiones específicas y cambiantes y, por tanto, "nunca es pasivo como sistema de dominación: está continuamente siendo renovado, recreado, defendido y modificado" (Polleri, s/f, en línea).

Sin embargo, el hecho objetivo de que la educación no es un mecanismo de reproducción mecánica inalterable de ninguna manera significa que la difusión ideológica deje de ser ejercida por el estado a través del profesorado. Lo que determina que nuestra primera necesidad como profesorado es comprender el funcionamiento de la hegemonía y situarnos, como profesores, en ese tejido.

Este es el problema sobre el que tenemos que pensarnos los docentes y resolver; nuestra necesidad de estudiar la educación de una manera no ingenua radica en no convertirnos en intelectuales orgánicos de la hegemonía establecida sin saberlo, en no interiorizar jaulas al estudiantado, a sus cabezas e ideas, tampoco a las nuestras.

Preguntémonos entonces, a propósito de precisar qué está específicamente unido a los intereses de clase dominante en lo que se enseña, ¿cómo identificar el entrelazado hegemónico en nuestras prácticas docentes? ¿qué nos determina, profesores de historia, como intelectuales orgánicos hegemónicos o contrahegemónicos? Siendo necesario complejizar esto, en el apartado siguiente examinaremos el insumo historiográfico.

\section{HISTORIOGRAFÍA E IDEOLOGÍA ESTATISTA}

Por razones teóricas y epistemológicas, la construcción de la actual disciplina historiográfica como tal, solo es posible en el siglo XIX y no antes. En el siglo XIX la historia adquiere como matriz disciplinar una noción de "realidad histórica", nutrida por los modelos de la ciencia; las críticas y discusiones historiográficas que germinarán en el siglo XX se levantan en torno a éstas ideas.

Examinaremos brevemente el realismo historiográfico del siglo XIX, problematizando la noción de fuente, la noción de objetividad y la noción de lo real con la que piensan y trabajan los historiadores decimonónicos. Éstos vehículos de análisis permiten desmontar 
las implicancias ideológicas de las producciones historiográficas con las que trabajamos los profesores de historia -se encuentren en los textos de los estudiantes o en nuestros propios papeles.

En primer lugar, los historiadores del siglo XIX están obsesionados con la fiabilidad del texto como fuente, suponiendo que lo escrito fija la realidad. Esta fuente constituiría un fragmento, un retazo de la realidad pasada que el historiador reúne, reconstruyendo el pasado; estos monumentos documentales reconstruidos entonces transparentarían la realidad pasada.

Es por esto que Ranke, representante ilustre de la historiografía realista decimonónica, quiere investigar "lo que realmente ocurrió" (1979: 38). Al encontrarse estos historiadores del siglo XIX convencidos de que la realidad reposa en las fuentes, creen que solo narran y describen la historia contenida en estas fuentes, ejerciendo un rol pasivo y neutral y otorgándole a la fuente un carácter ontológico, ${ }^{7}$ que autoriza los enunciados que respecto del pasado ejerce el historiador; las fuentes no son cuestionadas como producto histórico de una determinada articulación de poder.

El problema de esto es que los textos, en tanto que artefactos culturales e históricos, ya contienen una interpretación de los acontecimientos; nunca un texto es neutro porque nunca una interpretación es neutra: el texto ofrece una representación. Esto contraría una idea de cognoscente neutral y una fuente que se deja leer sin violentarla, basándose en que las fuentes ya son violentas; no son un reflejo de la realidad, sino productos históricos, lo que significa que deben ser estudiadas históricamente. Carlo Ginzburg, por ejemplo, señala que "el estado de la documentación refleja, como es lógico, el estado de las relaciones de fuerza entre las clases" (1999: 215).

Langlois, otro insigne tradicional decimonónico que entiende el documento escrito como una parte de la realidad, sentencia: "nada suple a los documentos, y donde no los hay, no hay historia" (1972: 17). Esta idea reducirá la producción historiográfica a una historiografía política basada exclusivamente en documentos oficiales de soporte estatista. ${ }^{8}$

Estas ideas, tanto de Ranke como de Langlois y las generaciones que influenciaron, marcarán a fuego la producción historiográfica, desde el siglo XIX hasta hoy. En palabras de Jean Chesneaux: "la gran mayoría de los "documentos oficiales", que tanto gustan a los historiadores, son de origen estatal o paraestatal" (1984: 37).

Estos documentos oficiales, forjados en las dinámicas del estado, y resguardados por el mismo, contienen, como dice Ranahit Guha (2002), una ideología estatista:

¿Quién decide lo que es histórico, y de acuerdo con qué valores y criterios? (...) en la mayoría de los casos la autoridad que hace la designación no es otra que una ideología para la cual la vida del estado es central para la historia. Es esta ideología, a la que llamaré

7 Incluso llegando a denominar unas fuentes - siempre escritas- como primarias y otras como secundarias según su grado de cercanía con la realidad.

8 Por si esto fuera poco, se excluye también a todas las sociedades ágrafas de la historia: por no tener documentos escritos, un pueblo no sería incorporable a la historia. La educación oficial en historia, coronada con las interrogantes memorísticas de la Prueba de Selección Universitaria, continúa preguntando qué es aquello que marca el paso, el quiebre, el cambio, de la llamada Pre-historia a la Historia, cuya respuesta esperada es justamente la invención de la escritura; Nos preguntamos entonces: ¿Cómo puede una sociedad, cómo pueden los hombres y mujeres, pre-existir a la historia? 
"estatismo", la que autoriza que los valores dominantes del estado determinen el criterio de lo que es histórico (17).

En conjunto, la institucionalización del estudio de la historia tuvo el efecto de asegurar una base estable al estatismo dentro de las disciplinas académicas y de promover hegemonía (18 y 19).

Hay en efecto algunas obras históricas que muestran tal preferencia y que son incapaces de hablar con otra voz que no sea la de la policía [...] (75).

La estúpida visión de la historia como una condenada cosa tras otra: levantamiento - información - decisión - orden (57 y 58).

Contrariando la idea decimonónica de reconstrucción del pasado mediante unos documentos, unos textos, unos fragmentos monumentales, neutros u objetivos, Guha está sosteniendo que la reconstrucción del pasado no es más que una CONSTRUCCIÓN historiográfica expresión de la ideología estatista y de los grupos dominantes, una construcción que se piensa a sí misma como reconstrucción; la historiografía no es una reconstrucción, es siempre una construcción, porque en su elaboración se delimitan los problemas, las preguntas, las fuentes y las hipótesis.

La historiografía tradicional decimonónica construye entonces, con unos documentos estatales y un criterio estatista, una historiografía ideológicamente estatal. Pero Guha advierte también, en el segundo párrafo expuesto, un asunto mayúsculo: la ideología estatista a su vez se sustenta en unos discursos legitimantes, a través de unos saberes que propagan, difunden, promueven hegemonía; las disciplinas no solo producen discursos, producen también campos de control social.

En esta relación entre historiografía, estado y hegemonía, la noción historiográfica decimonónica de realidad comprende una unicidad lineal de los acontecimientos, un modelo de temporalidad absoluta afín a las ciencias naturales, pero también a la idea de un solo mundo posible, acorde con la ideología estatal y burguesa de quietud, contrario a la idea de un presente constituido de encrucijadas. En esta construcción lineal se decretan unas verdades objetivas, en las que se determina qué es histórico y qué no lo es, visibilizando e invisibilizando, otorgándole carácter de agente histórico a unos y relegando a otros, borrando voces, sujetos, subjetividades; se articula así, de manera violenta y excluyente, una historiografía hegemónica y hegemonizante. ${ }^{9}$

Por todo esto Walter Benjamin, en sus Tesis de filosofía de la historia (1955), afirma contra la historiografía decimonónica que "no se trata de reconstruir los hechos tal cual realmente ocurrieron, sino de recuperarlos tal como relampaguean en este instante de peligro, porque si el enemigo triunfa $-\mathrm{y}$ hasta ahora no ha dejado de hacerlo- ni los muertos estarán a salvo" (en línea, parágrafo 6: 3 y 4).

A la historiografía decimonónica, académica-documental, que considera el hecho contenido en las fuentes, expresamos un reparo más. El hecho histórico, hemos señalado, no deriva de las fuentes, es el resultado de una construcción, de unas hipótesis, de unas tesis, un esfuerzo intelectual, una delimitación de un campo de problemas; es decir, el

$9 \quad$ Por ejemplo, Norbert Lechner ha señalado que "la construcción de una historia nacional implica "limpiarla" de toda encrucijada, eliminar las alternativas y las discontinuidades, retocar las pugnas y tensiones, redefinir los adversarios y los aliados, de modo que la historia sea un avance fluido que, como imagen simétrica, anuncia el progreso". (Cit. en Grez, en línea) 
hecho histórico es producido por el historiador, quien construye objetos de estudio ejerciendo conscientemente una producción cognoscente a través de materiales. Por esto la historia no es un relato y no puede ser una narración -aunque su modo de exposición sí puede serlo; porque lo que se produce historiográficamente es actividad intelectual que produce conocimiento. La historiografía, el conocimiento histórico, atraviesa un proceso sistemático y riguroso, que le significa ser un conocimiento científicamente elaborado, que se expresa en análisis, en explicaciones. Sin embargo, el discurso historiográfico decimonónico no se diferencia de otros contemporáneos, como el literario por ejemplo: ambos son narrativos y descriptivos, presumiendo los historiadores que la narración es explicativa. Roland Barthes (1994), refiriéndose al discurso de la historia, expresa que la narración histórica del siglo XIX se postula como una estrategia que produce un efecto de realidad, que supone que lo narrado en el discurso es "la realidad sida, lo realmente acontecido", y agrega:

[...] la declinación (si no la desaparición) de la narración en la ciencia histórica actual que procura hablar de las estructuras más que de las cronologías, implica mucho más que un simple cambio de escuelas. Se trata de una verdadera transformación ideológica; la narración histórica muere porque el signo de la historia es en adelante no tanto lo real como lo inteligible (Barthes, 1994: 50).

Esto, lo inteligible, es el último de nuestros alcances en este apartado. La relación entre el historiador y la realidad es siempre una relación mediatizada, en la que el historiador construye mediante problemáticas lo inteligible, pero lo inteligible no es lo real; lo inteligible es una estructura cognitiva. Para inteligir construimos teoría, construimos conceptos, construcciones que no son la realidad, sino un acercamiento teórico asintótico -es decir, que nunca acaba, que nunca concluye- a la realidad. El discurso histórico es un discurso inteligible, que al ser una relación mediatizada, nunca puede ser objetivo, sino atravesado por ideología.

La superación de esta historiografía decimonónica errada radica en abandonar un tipo de realismo que confunde la aproximación con la realidad; abandonar la narrativa histórica del siglo XIX que se pretende a sí misma realista implica abandonar también la idea de objetividad posible en la historiografía. Abandono que resulta insostenible sin el desmonte de las nociones historiográficas que hemos intentado trazar aquí; si no queremos reproducir una historiografía estatista en las escuelas, una hegemonía mediante la pedagogía en historia, es necesario examinar los saberes que habitan nuestras fuentes historiográficas e históricas. ${ }^{10}$

10 Lucien Febvre, refiriéndose a estas discusiones historiográficas, a las que tanto colaboró junto a Marc Bloch y Henri Berr entre otros, piensa con tinta: “¿Es una derrota de las viejas ideas, de las viejas doctrinas anonadadas por las nuevas que irrumpen? No tanto. Nunca hubo mar geológico que no dejara un estrato atestiguando su potencia" (1986: 28). Y pensamos que está en lo cierto. Así como evidenciamos la presencia del estatismo y su hegemonía en la historiografía escolar, la historiografía decimonónica narrativa y descriptiva, que se pretende objetiva, sigue respirando saludable en las escuelas formadoras de profesores de historia; por esto, que el análisis de la explosión de 1914 se centre en el imperialismo y no en el atentado de Sarajevo, sigue siendo hoy un campo de disputa. 


\section{CONSIDERACIONES PARA NO SER ECO DE UNA HISTORIOGRAFÍA ESTATISTA DE VOZ POLICIAL}

Al finalizar el primer apartado, nos preguntábamos cómo identificar la hegemonía atada a nuestras prácticas docentes, y gastamos el segundo apartado en examinar unas nociones teóricas que visibilizaran y vehiculizaran nuestras críticas a la historiografía que alimenta aquella hegemonía. A través de esto hemos establecido que ni el profesor de historia ni el historiador pueden suponerse objetivos o neutrales, como tampoco lo son los saberes que producen, ni los medios de producción de los mismos; las fuentes, los conceptos, los problemas e incluso las palabras con las que trabajamos están atravesadas por relaciones ideológicas. Establecido esto, este tercer apartado está escrito pensando en una resistencia del profesorado a una pedagogía en historia como caja de resonancia de una historiografía hegemónica estatal.

Sabemos que, como señalaba Althusser (1974), muchos profesores son rebasados y aplastados por el sistema educacional; no logran quebrar la hegemonía en la que el educador fue educado y la difunden, enseñando en sus clases, en sus contenidos, una historiografía ideológicamente estatista, oficial, policial. Pero sabemos mejor que esta hegemonía no es inquebrantable; que el profesor de historia conoce la experiencia colectiva tras él y piensa sobre ella -porque en esto radica fundamentalmente su trabajo-, que tiene herramientas históricas e historiográficas, que respira la historia que está siendo, que ejerce sobre ella sus intervenciones ideológicas y políticas y que la historia ejerce otras sobre él, y en esta relación combate, transmite, aprende, enseña, se agota y regenera colectivamente como el oleaje, con otras ideas, otras generaciones, otras luchas; siendo capaz entonces de volver la inteligencia, el pensamiento y la experiencia de sus estudiantes contra la dominación ideológica que circunscribe los saberes posibles.

Para sortear el cerco hegemónico que transforma el ejercicio docente del profesorado en historia en un eco de una historiografía ideológicamente estatista y de vocabulario policial, apuntamos dos consideraciones: la primera devela la incompatibilidad del estudio serio de la historia con los márgenes establecidos por el estado; la segunda centra el trabajo del profesor de historia en el presente fulgurante.

4.1. El estado está totalmente implicado en el desarrollo de nuestras condiciones históricas, con una complicidad que no puede evidenciar como conflicto, como dominación, como control, como disciplinamiento; esto es una limitación a un estudio histórico crítico porque incompatibiliza los saberes bajo el signo de la ilegalidad. Este filtro policial -guardián en los contenidos escolares y en los textos de los estudiantes, pero también en la formación del profesorado- invisibiliza la alteridad, condicionando las rebeldías, las subversiones, no como indignación, no como resistencias a una dominación, sino como ILEGALES por definición; como si lo ilegal no fuera una relación histórica gestada por la dominación de unas clases, y por tanto, dinámica, sujeta a transformación.

Esta participación del estado en la educación histórica de las masas, ejerce unos márgenes, establece unos bordes trazados como cortafuegos historiográficos hegemónicos; desvincula al estado de sus nefastos manotazos gorilas, a los regimientos con pobladores en el fondo del mar y a las comisarías con profesores degollados; obligándonos a repensar nociones vertebrales para el estudio histórico: por ejemplo, que paz no significa exclusivamente el término de unos conflictos, sino también la conquista de una determinada 
dominación; y que esta dominación, en tanto control y coerción jurídico-policial, es violenta. "Al río que todo lo arranca todos lo llaman violento, decía Bertolt Brecht, pero nadie llama violento al lecho que lo oprime".

La resignificación de la violencia -lejos de un criterio propio de la autoridad, que encumbra la violencia nacionalista, condena la violencia popular e invisibiliza la violencia estatal- es gravitante porque, como elemento vertebral de los procesos históricos, no puede generarse un estudio crítico de las fuerzas históricas que forjan el presente ignorando el rol de la violencia del estado, o justificándola como legal, como natural, que es lo mismo que deshistorizarla.

En suma, un aprendizaje histórico crítico no es producible por el estado, porque la selección arbitraria de los saberes se traduce en una historia monofónica, lineal, que habla con la voz del estado y de la policía, naturalizándolos, como si fueran un agente neutro, cuando en verdad están situados irremediablemente en la sujeción de las condiciones de explotación, de rebeldía, castigo y prisión, de tala y cultivo, es decir, de lucha. El profesor de historia, como catalizador o saboteador de los saberes ideológicamente estatistas, tiene que elegir el parapeto que defiende: la hegemonía estatal o el desarrollo del pensamiento crítico. La ingenuidad de los profesores de historia respecto de esto los transforma en gendarmes del orden establecido.

4.2. El profesor de historia no está condenado a transformar su práctica pedagógica en eco de una historiografía oficial, estatal, policial, porque al enseñar historia ejerce una selección de sus herramientas, que son básicamente las fuentes históricas e historiográficas. Por el contrario, cuando el profesor de historia no ejerce esta selección de fuentes de manera consciente, reduciendo esta selección al texto del estudiante y a los programas de estudio (que son también una selección de fuentes historiográficas e ideológicas), cuando no es capaz de leer críticamente estas fuentes, de precisar qué está específicamente unido a los intereses de clase dominante en lo que se enseña, el profesor de historia se vuelve un reproductor, una caja de resonancia de una historiografía hegemónica estatal.

Entonces interrogamos nuestros insumos historiográficos para no hacer de la pedagogía en historia el eco difusor de una historiografía policial; es decir, una historiografía que propaga y reproduce un razonamiento propio de la autoridad $\mathrm{y}$, hablando desde la legalidad y el orden, minimiza la alteridad, levantando cercos ideológicos de obediencia y control que normalizan la dominación al no presentarla como una situación histórica, es decir, alterable. De este examen, recogemos algunas consideraciones para el trabajo del profesorado en historia.

En primer lugar, el profesor de historia, como nosotros lo entendemos, no encuentra las ruinas del pasado, sino que transforma el pasado en ruinas, para construir con esos restos el presente fulgurante, urgente, que movilice la experiencia en un hacer la historia además de estudiarla (Grüner, 2005: 26). ${ }^{11}$ Lo que equivale a decir que no se estudia historia para aprender historia, sino para poner la praxis acumulada, la experiencia colectiva, en las cabezas y los brazos de los estudiantes que hacen este presente fulgurante en el que nada está resuelto de antemano porque, es necesario insistir: la historia no fue, la historia está siendo.

11 Laidea es de Walter Benjamin. Nosotros escribimos "profesor de historia" donde Benjamin escribe "historiador materialista". 
Siguiendo con Benjamin, estudiar historia "no se trata de reconstruir los hechos tal cual realmente ocurrieron", sino de recuperarlos "tal como relampaguean en este instante de peligro"; no se trata de estudiar historia como se amontonan migajas, dice Chesneaux, y ejemplifica: "no queremos más información acumulada de la alimentación del siglo XVII para apenas saber quién come bien y quién come mal, ni por qué, ni el papel del hambre y de la saciedad en el equilibrio de las fuerzas políticas, y en las luchas de clases" (1984: 171); sino extrapolar esto a nuestras condiciones históricas en el desarrollo de las luchas de clases.

Por todo esto, la docencia en historia, como la historiografía, no es una reconstrucción, sino siempre una construcción en donde se delimitan los problemas, las preguntas, las fuentes y las hipótesis de trabajo. En este delimitar reconocemos la médula del trabajo del profesorado en historia, donde radica la diferencia capital que divide a los maestros de escuela: la articulación de sus clases en función del presente fulgurante; o la reproducción de unas articulaciones ya delimitadas.

Esta resignificación en función del presente fulgurante permite dar saltos de cirquero sobre el respeto a la legalidad e ilegalidad como filtro y, por tanto, a la idea de un único mundo posible, dirigido por autoridades y policías; un filtro que invisibiliza a sujetos históricos que, capaces de entender las fuerzas históricas inmediatas que los condicionaban (condicionan), las rechazaron (rechazan) en rebeldía, en discordia. Nosotros, los profesores de historia, vehiculizamos esto a través de las fuentes históricas: traemos a las escuelas unos mundos de alteridad o los negamos, haciéndolos irreconocibles. ${ }^{12}$

Trastocados los tejidos populares, desarticulada esa relación orgánica de presente y pasado, ${ }^{13}$ la responsabilidad del profesor de historia en nuestras condiciones históricas posdictadura de contrarrevolución neoliberal madura, nos obliga a hacernos cargo de nuestro rol de intelectuales orgánicos situados en el nervio del entendimiento sociohistórico y político para las masas estudiantiles.

Los discursos oficiales que, reunidos en torno a la idea del fin de la historia, desdibujan un mundo sostenido en la dominación de unas clases por otras, ejercen también una discontinuidad del nosotros, nervio de la comprensión histórica. Quienes incorporamos la alteridad, para hacer menos irreconocibles esos mundos, interiorizando esas resistencias, esas selvas, montañas, calles y fábricas, lo hacemos -tenemos que hacerlo- en torno a la idea del nosotros. Mas toda idea del nosotros obliga a diferenciarnos de un ellos. Diferenciación que no nos corresponde determinar; si nuestro trabajo ha de centrarse en la comprensión del presente fulgurante, histórico, dinámico, alterable, lo que nos atañe es entregar las herramientas, las categorías de análisis que faciliten esta comprensión a las masas estudiantiles, que les permita ejercer la determinación del nosotros -y la diferenciación del ellos- en las experiencias y proyectos históricos colectivos que materialicen.

12 Que tan lejana o cercana nos parezca una América Latina convulsionada de las postrimerías del siglo XX, se relaciona, por ejemplo, con un estudio serio del Sendero Luminoso del Perú de los ochentas, o un EZLN en el México palpitante; coyunturas explicativas de la continuidad y cambio en la monstruosa complejidad histórica del continente, de desesperación de las masas y la dignidad rebelde, de gobiernos, policías y ejércitos.

13 Eric Hobsbawm escribía en 1994: "La destrucción del pasado, o más bien de los mecanismos sociales que vinculan la experiencia contemporánea del individuo con la de generaciones anteriores, es uno de los fenómenos más característicos y extraños de las postrimerías del siglo XX. En su mayor parte, los jóvenes, hombres y mujeres, de este final de siglo crecen en una suerte de presente permanente sin relación orgánica alguna con el pasado del tiempo en el que viven" (2007: 13). 


\section{CONCLUSIÓN}

Gabriel Salazar (2006) ha señalado que el sistema educativo chileno enseña a los estudiantes a reproducir el sistema, enseñando obediencia, potenciando la gobernabilidad del sistema; lo que es innegable, pero, como expusiéramos en los apartados anteriores, sistema educativo no es igual a profesor. El profesor de historia, aunque trabajador del sistema educativo, está en posición de sabotaje a esta parcela de reproducción de la hegemonía estatal en tanto es consciente de cómo y porqué ésta opera, de la gravitancia que en ella adquieren los profesores, y de su implicancia en las relaciones de dominación a través de los procesos de subjetivación de los estudiantes como sujetos históricos. ${ }^{14}$

Por lo tanto, en las clases de historia están las condiciones para enseñar a pensar de manera explícita y deliberada, para dirigir el razonamiento crítico de los estudiantes, en la medida en que en el profesor de historia y en sus herramientas, las fuentes históricas e historiográficas, estén las condiciones intelectuales para rechazar una historiografía policial revestida de saberes objetivos que invisibilizan la alteridad. Para esto se requiere saber desalambrar la "mala historia", que Eric J. Hobsbawm dice, "no es historia inofensiva, sino peligrosa" (2008: 276).

\section{REFERENCIAS BIBLIOGRÁFICAS}

Althusser, L. (1974). Ideología y aparatos ideológicos del estado. Freud y Lacan. Buenos Aires: Nueva Visión.

Barthes, R. (1994). El susurro del lenguaje. Más allá de la palabra y la escritura. Barcelona: Editorial Paidós.

Benjamin, W. Tesis de filosofía de la historia. Revolta Global. En línea, disponible en: http://www. archivochile.com/Ideas_Autores/benjaminw/esc_frank_benjam0007.pdf (8/9/2011).

Bourdieu, P. y Passeron, J. C. (1996). La Reproducción. Elementos para una teoría del sistema de enseñanza. Barcelona: Editorial Laia.

Campione, D. (2010). Antonio Gramsci. Breves apuntes sobre su vida y su pensamiento. En línea; disponible en: http://es.scribd.com/doc/8636750/Daniel-Campione-Antonio-Gramsci-Brevesapuntes-sobre-su-vida-y-pensamiento (8/9/2011).

Ciataloni, F. (1996). El hijo del pelícano puede matar al padre. En P. Bourdieu y J. C. Passeron, La Reproducción. Elementos para una teoría del sistema de enseñanza (pp. 25-31). Barcelona: Editorial Laia.

Chesneaux, J. (1984). ¿Hacemos tabla rasa del pasado? A propósito de la historia y los historiadores. Buenos Aires: Siglo XXI.

Febvre, L. (1986). Combates por la historia. Barcelona: Planeta-Agostini.

Foucault, M. (2003). La verdad y las formas jurídicas. Barcelona: Gedisa.

Ginzburg, C. (1999). El queso y los gusanos. El cosmos según un molinero del siglo XVI. Barcelona: Ediciones Península.

Gramsci, A. (1986). Cuaderno 12 (XXIX) 1932. Apuntes y notas dispersas para un grupo de ensayos sobre la historia de los intelectuales. En: A. Gramsci, Cuadernos de la cárcel. México: Ediciones Era.ç

14 El viejo Pierre Vilar decía en 1987 que "pensar históricamente es la educación histórica general que se debería dar a todos; pero que esto es demasiado peligroso para los poderes establecidos, para las ideologías dominantes" (En línea). 
Grez, S. Historiografía, memoria y política. Observaciones para un debate. Cyber Humanitatis, n. 41. En línea; disponible en: http://www.revistas.uchile.cl/index.php/RCH/article/viewArticle/10514/10568 (8/9/2011)..

Grüner, E. (2005). Marx, historiador de la praxis. Estudio introductorio. En: K. Marx, Las luchas de clases en Francia de 1848 a 1850 (pp. 11-96). Buenos Aires: Ediciones Luxemburg.

Gruppi, L. (1978). El concepto de hegemonía en Gramsci. México: Ediciones de Cultura Popular.

Guha, R. (2002). Las voces de la historia y otros estudios subalternos. Barcelona: Editorial Crítica.

Hobsbawm, E. J. (2007). Historia del siglo XX. Buenos Aires: Editorial Crítica.

Hobsbawm, E. J. (2008). Sobre la historia. Madrid: Editorial Crítica.

Langlois, C. y Seignobos, C. (1972). Introducción a los estudios históricos. Buenos Aires: Editorial La Pléyade.

Polleri, F. La hegemonía cultural. En línea; disponible en: http://www.gramsci.org.ar/12/polleri_heg_cult_lucha.htm (8/9/2011).

Popkewitz, T. (2000). Sociología política de las reformas educativas. El poder/saber en la enseñanza, la formación del profesorado y la investigación. Madrid: Ediciones Morata.

Poulantzas, N. (1986). Hegemonía y dominación en el Estado moderno. México: Siglo XXI.

Rosas, P. (2004). Rebeldía, subversión y prisión política. Crimen y castigo en la transición chilena 1990-2004. Santiago: LOM Ediciones.

Ranke, L. (1979). Historia de los pueblos latinos y germánicos de 1494 a 1514. México: Ediciones Fondo de Cultura Económica.

Salazar, G. (2006). El profesor debe ser ante todo y toda la vida un investigador. Revista Docencia, n. 30, 64-70. 